\title{
Preparation of Amidoxime Adsorbent by Radiation Induced Grafting of Acrylonitrile on Polyethylene Film and Its Application in Cr(VI) Removal
}

\author{
Nazia Rahman, ${ }^{*}$ Nirmal Chandra Dafader, Abdur Rahim Miah, \\ Md. Ferdous Alam and Shahnaz Sultana
}

Nuclear and Radiation Chemistry Division, Institute of Nuclear Science and Technology, Atomic Energy Research Establishment, Bangladesh Atomic Energy Commission, G. P. O. Box-3787, Dhaka, Bangladesh

${ }^{*}$ Corresponding author: naziabaec@gmail.com

Published online: 25 August 2018

To cite this article: Rahman, N. et al. (2018). Preparation of amidoxime adsorbent by radiation induced grafting of acrylonitrile on polyethylene film and its application in Cr(VI) removal. J. Phys. Sci., 29(2), 65-88, https://doi.org/10.21315/jps2018.29.2.5

To link to this article: https://doi.org/10.21315/jps2018.29.2.5

\begin{abstract}
Pre-irradiation technique was applied to graft acrylonitrile (AN) onto polyethylene film. The graft yield was optimised with respect to radiation dose, monomer concentration and reaction time. $\mathrm{H}_{2} \mathrm{SO}_{4}$ was added to the monomer solution to improve the graft yield. The highest graft yield obtained was $120 \%$ at $70 \mathrm{kGy}$ radiation dose, $60 \%$ monomer concentration and $4 \mathrm{~h}$ reaction time using $\mathrm{H}_{2} \mathrm{SO}_{4}$ as additive. The AN grafted films were modified with hydroxyl amine hydrochloride to prepare amidoxime adsorbent. The prepared adsorbent was characterised by using Fourier transform infrared (FTIR), nuclear magnetic resonance (NMR), thermogravimetric analysis (TGA) and dynamic mechanical analysis (DMA). The prepared amidoxime adsorbent showed high affinity towards Cr(VI) adsorption. Adsorption capacity was studied under different conditions: contact time, $\mathrm{pH}$ and initial metal ion concentration. The highest adsorption capacity obtained was $200 \mathrm{mg} \mathrm{g}^{-1}$ of adsorbent after $72 \mathrm{~h}$ contact time at $\mathrm{pH} 1.5$ and initial metal ion concentration 200 ppm. Pseudo-first-order and pseudo-second-order equations were used for interpretation of kinetic adsorption data. The equilibrium experimental data of $\mathrm{Cr}(V I)$ adsorption were also fitted with Langmuir isotherm model. Desorption and reuse of the adsorbent film was studied. The adsorbent showed no significant loss of adsorption capacity upon repeated use.
\end{abstract}

Keywords: Pre-irradiation technique, acrylonitrile, amidoxime adsorbent, $\mathrm{Cr}(\mathrm{VI})$ sorption, radiation induced grafting 


\section{INTRODUCTION}

In recent years, heavy metal pollution has become one of the most severe environmental problems and a great attention has been given to chromium because of its high toxicity to both the environment and living organisms. ${ }^{1-3}$ Various industries and manufacturing plants such as tanneries, paints and pigments, electroplating, metal processing, wood preservatives, textile, dye industry, steel fabrication and canning use chromium for various applications and discharge large quantity into the environment. ${ }^{4-6}$ In aquatic systems, chromium exists mainly as $\mathrm{Cr}(\mathrm{VI})$ and $\mathrm{Cr}(\mathrm{III})$ species which differ considerably in toxicity. $\mathrm{Cr}(\mathrm{III})$ species are considered an essential trace element for the metabolism in mammals. Conversely, $\mathrm{Cr}(\mathrm{VI})$ species are carcinogenic and extremely toxic. ${ }^{7,8}$ Moreover, $\mathrm{Cr}(\mathrm{VI})$ has a higher solubility and mobility than $\mathrm{Cr}$ (III) species increasing its dangerous effects. Chromium is non-biodegradable; it enters into the body through breathing, eating, drinking or skin contact of chromium and its compounds. The toxic effects of $\mathrm{Cr}(\mathrm{VI})$ include skin rashes, nose bleeding, respiratory tract infection, suppressed immune system, hepatic diseases and lung cancer., ${ }^{9}$, Hence, it is important to eliminate traces of chromium from drinking water, or to remove chromium from wastewaters before they are discharged into receiving bodies.

Several methods have been used for the removal of $\mathrm{Cr}(\mathrm{VI})$ from industrial wastewatersincludingion-exchange, solventextraction, filtration andadsorption. ${ }^{11-14}$ Adsorption has been most widely used due to relatively low-cost, availability, ease of operation and efficiency in comparison with other conventional methods. ${ }^{15}$ For this purpose, many types of adsorbents have been investigated for the removal of chromium including activated carbon, biomaterials and nanomaterials. ${ }^{15-24}$

Recently, many researchers have focused attention on grafted polymers as alternative heavy metal adsorbent. ${ }^{25-35}$ "Grafting" is a method in which functional monomers are covalently bonded onto the backbone polymer chain. Graft polymerisation allows incorporation of various functions possessed by the grafted monomer to the parent polymer while maintaining the mechanical properties of the parent polymer. ${ }^{36,37}$ Among the different methods for initiating graft copolymerisation like ionising radiation, ultraviolet light, plasma treatment, decomposition of chemical initiators, oxidation of polymers, etc., radiation-induced grafting technique is advantageous because of its extensive penetration into the polymer matrix and its rapid and uniform formation of radicals. ${ }^{38}$

Polyethylene (PE) has been selected as the base polymer to prepare the adsorbent for its excellent mechanical and thermal property and low cost. A number of researchers have studied single or binary monomer grafted PE film for heavy metal ion adsorption. ${ }^{39-42}$ A polymeric adsorbent material based on PE was prepared by 
photo grafting of 2-(dimethylamino)ethyl methacrylate (DMAEMA) monomer on to a PE film and investigated for $\mathrm{Cr}(\mathrm{VI})$ removal. ${ }^{43}$ Composite particles were synthesised using titanium oxide attached to PE films by plasma techniques and used for the removal of $\mathrm{Cr}(\mathrm{VI})$ from aqueous solutions in batch systems. ${ }^{44}$

Present study focuses on preparation of a new adsorbent by radiation induced grafting of acrylonitrile (AN) on PE films and its application in $\mathrm{Cr}(\mathrm{VI})$ removal. Pre-irradiation technique was employed in the grafting of AN on PE film. The graft yield was optimised with respect to radiation dose, monomer concentration and reaction time. $\mathrm{H}_{2} \mathrm{SO}_{4}$ was added to the monomer solution to improve the graft yield. The AN grafted films were modified with hydroxyl amine hydrochloride to prepare amidoxime adsorbent. The amidoxime adsorbent has been used to adsorb $\mathrm{Cr}(\mathrm{VI})$ ion from aqueous solution. Adsorption capacity was studied under different conditions: contact time, $\mathrm{pH}$ and initial metal ion concentration. Desorption and reuse of the adsorbent film was also investigated.

\section{EXPERIMENTAL}

\subsection{Materials and Reagents}

PE films (thickness $0.04 \mathrm{~mm}$ ) were collected from Chakbazar, Dhaka, Bangladesh. These films were cut into small pieces $\left(12 \times 1.5 \mathrm{~cm}^{2}\right)$, washed with methanol and dried in oven before use. Monomer acrylonitrile (BDH, UK) was used as received. Methanol, sodium carbonate, sulphuric acid, acetone and 1, 5-diphenylcarbazide were obtained from Merck, Germany. Hydroxyl amine hydrochloride was supplied by Sigma Aldrich, USA. Potassium dichromate (Techno Pharmchem, India) was used for metal adsorption study.

\subsection{Instrument and Apparatus}

The PE films were characterised by Fourier transform infrared (FTIR) ATR spectrophotometer (8400S Shimadzu Japan) in the $700-4000 \mathrm{~cm}^{-1}$ range (resolution $4 \mathrm{~cm}^{-1}$, number of scans 20 times). ${ }^{1} \mathrm{H}$ NMR spectra were measured at $25^{\circ} \mathrm{C}$ on Bruker Advance DPX $400 \mathrm{NMR}$ instrument operating at $400 \mathrm{MHz}$ in the Fourier transform mode (benzene was used as the solvent). The thermo gravimetric analysis was performed with TGA-50 (Shimadzu, Japan) from $25^{\circ} \mathrm{C}$ to $500^{\circ} \mathrm{C}$

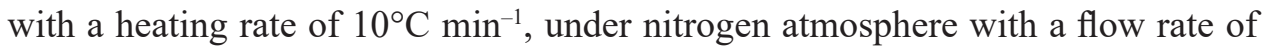
$20 \mathrm{ml} \mathrm{min}^{-1}$. The dynamic mechanical properties of the adsorbent were studied from $25^{\circ} \mathrm{C}$ to $80^{\circ} \mathrm{C}$ at a heating rate of $4^{\circ} \mathrm{C} \mathrm{min}^{-1}$ and an oscillating frequency of $1 \mathrm{~Hz}$ using dynamic mechanical analyser (DMA), Triton Technology TTDMA, UK. The metal-ion concentrations in the solutions were analysed spectrophotometrically 
(UV-2401PC, Shimadzu, Japan). The radiation source used for grafting experiment was Co-60 gamma ray. It is a $90 \mathrm{kCi}$ Cobalt-60 Batch Type Panoramic Irradiator (Board of Radiation and Isotope Technology, BRIT, India). Activity was $68.63 \mathrm{kCi}$ and dose rate was $13.7 \mathrm{kGy} \mathrm{h}^{-1}$.

\subsection{Grafting of AN onto the PE Films by Gamma Radiation}

The PE films were irradiated by gamma radiation from Co-60 source at different radiation doses ( $30 \mathrm{kGy}, 50 \mathrm{kGy}$ and $70 \mathrm{kGy}$ ) at ambient temperature. The irradiated $\mathrm{PE}$ films were stored in dry-ice temperature until use. The monomer solution was prepared by adding $\mathrm{AN}(20 \%, 40 \%$ and $60 \%)$ and $\mathrm{H}_{2} \mathrm{SO}_{4}(2 \%$ of $\mathrm{AN})$ to methanol. The monomer solution was bubbled with nitrogen gas to remove dissolved oxygen. The de-aerated monomer solution was poured into glass bottle containing irradiated PE films. After completely filling the glass bottle with monomer solution, the bottle was tightly closed with a lid to prevent inclusion of oxygen from air into the monomer solution of bottle. After that the grafting reaction was carried out at $80^{\circ} \mathrm{C}$ in a water bath for different period of time $(1 \mathrm{~h}, 2 \mathrm{~h}, 3 \mathrm{~h}$ and $4 \mathrm{~h})$. The AN-g-PE fabric was washed with methanol to remove residual monomer and homopolymer of AN. The degree of grafting was calculated as follows:

$$
\text { Degree of grafting }(\%)=\left[\left(\mathrm{W}_{1}-\mathrm{W}_{0}\right) / \mathrm{W}_{0}\right] \times 100
$$

where, $\mathrm{W}_{1}$ is the dry weight of grafted PE film and $\mathrm{W}_{0}$ is the dry weight of PE film.

\subsection{Amidoximation of Nitrile Group of AN Grafted PE Film}

An $80 \mathrm{~g} \mathrm{l}^{-1}$ aqueous solution of hydroxyl amine hydrochloride was prepared in distilled water by stirring with a glass rod and it was neutralised by adding sodium carbonate. The AN grafted PE (AN-g-PE) films were placed into the aqueous solution of hydroxyl amine hydrochloride and heated in water bath at $80^{\circ} \mathrm{C}$ for $4 \mathrm{~h}$. The films were then washed three times with distilled water in order to remove the remaining salts and were dried in air. To study the effects of the reaction conditions on the conversion of the nitrile group to the amidoxime group, the reaction time was varied from $2 \mathrm{~h}$ to $4 \mathrm{~h}(2 \mathrm{~h}, 3 \mathrm{~h}$ and $4 \mathrm{~h})$ with the concentration of $\mathrm{NH}_{2} \mathrm{OH}$. $\mathrm{HCl}$ was varied from $4 \%$ to $16 \%(4 \%, 8 \%$ and $16 \%)$ and $\mathrm{pH}$ was varied from 5 to 9 (5, 7 and 9). The conversion of nitrile group of AN-g-PE film was calculated using the following equation:

$$
\mathrm{C}_{\mathrm{n}}=\left[\left(\mathrm{W}_{2}-\mathrm{W}_{1}\right) / \mathrm{W}_{1}\right] \times\left[\mathrm{M}_{0} / \mathrm{M}_{1}\right] \times 100
$$

where $\mathrm{W}_{1}$ is the weight of the grafted $\mathrm{PE}$ film before the reaction, $\mathrm{W}_{2}$ is the weight of the grafted film after the reaction, $\mathrm{M}_{0}$ is the molecular weight of the acrylonitrile 
monomer (53 $\mathrm{g} \mathrm{mole}^{-1}$ ) and $\mathrm{M}_{1}$ is the molecular weight of the hydroxyl amine $\left(33 \mathrm{~g} \mathrm{~mole}^{-1}\right) \cdot{ }^{45}$

The preparation scheme of amidoxime adsorbent is shown in Figure 1.

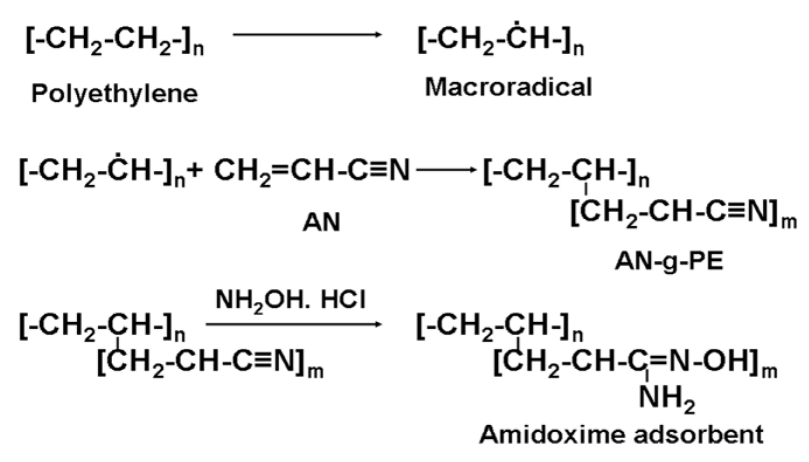

Figure 1: Preparation scheme of amidoxime adsorbent.

\subsection{Metal Ion Adsorption by Amidoximated PE film}

The amidoximated PE films were soaked into the $50 \mathrm{ml}$ aqueous solutions of $\mathrm{Cr}(\mathrm{VI})$ at room temperature $\left(25^{\circ} \mathrm{C}\right)$. The adsorption process was carried out at different $\mathrm{pH}$, contact time and initial metal ion concentration. The $\mathrm{pH}$ of the solutions was adjusted using $\mathrm{HCl}$ and $\mathrm{NaOH}$ solution. The metal-ion concentrations of the solutions before and after adsorption were analysed by UV spectrophotometer. The metal ion uptake capacity of the film was calculated as follows:

$$
\mathrm{Q}=\mathrm{V}\left(\mathrm{C}_{1}-\mathrm{C}_{2}\right) / \mathrm{W}
$$

where $\mathrm{Q}$ is the adsorption amount ( $\mathrm{mg} \mathrm{g}^{-1}$ of adsorbent), $\mathrm{W}$ the weight of the amidoximated PE film (g), $\mathrm{V}$ the volume of solution (1), and $\mathrm{C}_{1}$ and $\mathrm{C}_{2}$ are the concentrations $\left(\mathrm{mg} \mathrm{l}^{-1}\right)$ of metal ion before and after adsorption respectively.

\subsection{Desorption of Metal Ions}

The desorption of $\mathrm{Cr}(\mathrm{VI})$ ions from the adsorbent films were carried out by the treatment with $2 \mathrm{M}$ aqueous solution of $\mathrm{NaOH}$ for $20 \mathrm{~h}$. The percent desorption was calculated using the following equation:

Percent desorption $=($ Ions desorbed $(\mathrm{mg}) /$ Ions adsorbed $(\mathrm{mg})) \times 100$ 


\section{RESULTS AND DISCUSSION}

\subsection{Grafting of AN on PE Film}

In the present study, pre-irradiation technique was employed for grafting of AN on PE film. In the pre-irradiation technique, the polymer backbone was first irradiated to form free radicals and the irradiated polymer substrate was then treated with the monomer as a solution in a suitable solvent. Since the monomer is not exposed to radiation in the pre-irradiation technique, the obvious advantage is that the method is relatively free from homo-polymer formation. In the present research, the graft yield was optimised with respect to monomer concentration and reaction time (Figure 2). It was observed that with the increase of the monomer concentration from $20 \%$ to $60 \%$, the graft yield increased from $4 \%$ to $30 \%$ at $4 \mathrm{~h}$ reaction time. Thus, the increase in the monomer concentration improved the graft yield. It may be explained as following: with the increase of monomer concentration more monomer molecules can come in contact with the PE free radical to react and form AN-g-PE. Again, it was observed that the graft yield increased with the increase of the reaction time $(1-4 \mathrm{~h})$. The increase of the graft yield with respect to the reaction time is fast up to $3 \mathrm{~h}$ and then it became slow. The results indicated that $1 \mathrm{~h}$ reaction time is not sufficient for grafting of $\mathrm{AN}$ on $\mathrm{PE}$ and $4 \mathrm{~h}$ reaction time is enough for satisfactory grafting of AN on PE film.

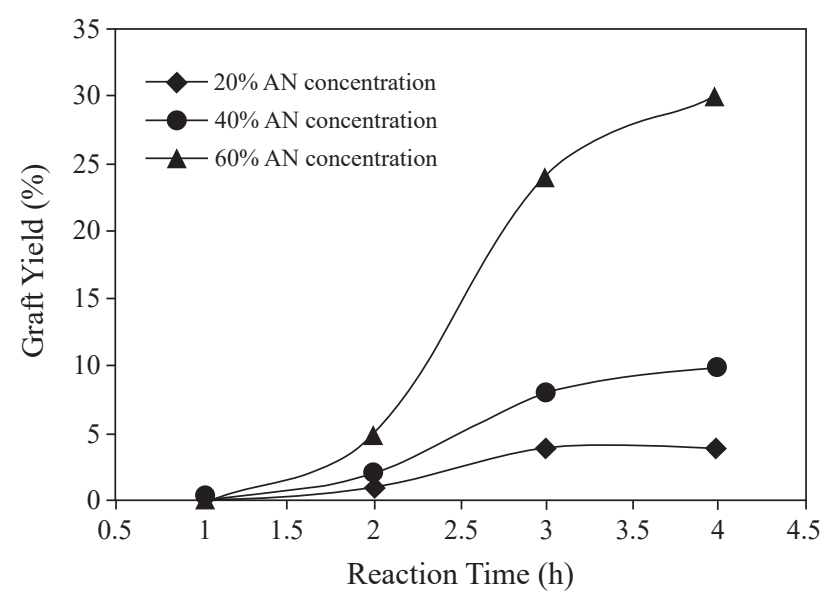

Figure 2: Effect of reaction time and monomer concentration on graft yield (radiation dose $70 \mathrm{kGy}$ ).

To improve the graft yield of $\mathrm{AN}$ on $\mathrm{PE}$ film, $\mathrm{H}_{2} \mathrm{SO}_{4}(2 \%$ of $\mathrm{AN})$ was added as additive to the monomer solution. Figure 3 shows the effect of addition of $\mathrm{H}_{2} \mathrm{SO}_{4}$ on graft yield. In this investigation, the monomer concentration was kept at $60 \%$ and radiation dose at $70 \mathrm{kGy}$. It was found that the addition of $\mathrm{H}_{2} \mathrm{SO}_{4}$ to the 
monomer solution largely improved the graft yield. The graft yield obtained with additive was $120 \%$ and without additive was $30 \%$ (at $4 \mathrm{~h}$ reaction time). It is documented that the addition of inorganic acids accelerates graft-copolymerisation in many systems. ${ }^{46}$ It is expected that the added sulphuric acid can give rise to the destruction of ordered arrangement of the molecules in crystalline domain of PE which accelerates the penetration of monomers for grafting into crystalline region accordingly.

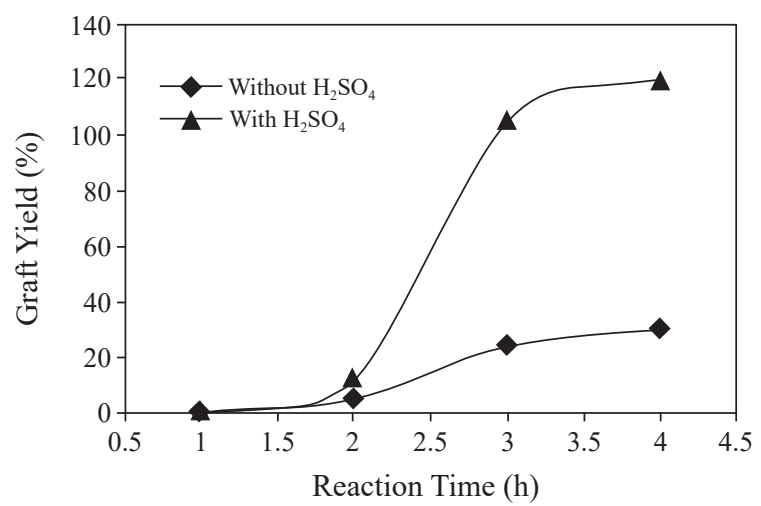

Figure 3: Effect of $\mathrm{H}_{2} \mathrm{SO}_{4}$ on graft yield (radiation dose $70 \mathrm{kGy}$, monomer concentration $60 \%)$.

Figure 4 represents the effect of radiation dose on graft yield of AN onto PE film. It was observed that with increasing radiation dose ( $30 \mathrm{kGy}$ to $70 \mathrm{kGy}$ ), the graft yield increased. The graft yields obtained are $80 \%, 100 \%$ and $120 \%$ for $30 \mathrm{kGy}$, $50 \mathrm{kGy}$ and $70 \mathrm{kGy}$ radiation dose, respectively. The results suggest that with increase of radiation dose more free radicals are formed on PE film which may react with monomer.

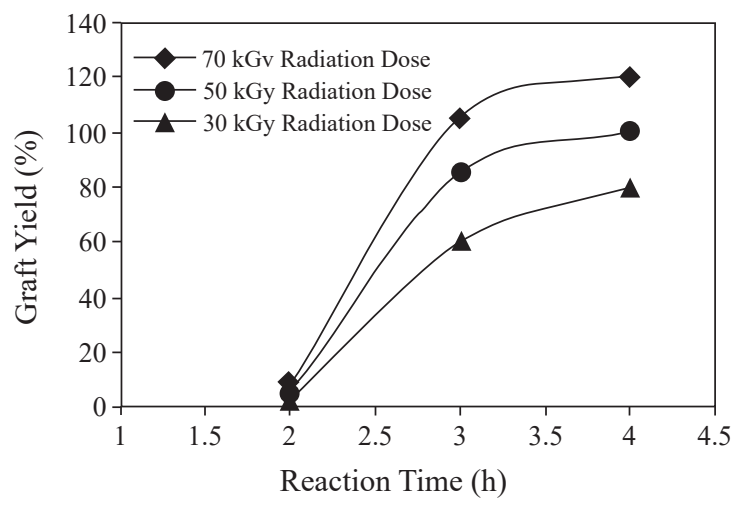

Figure 4: Effect of radiation dose on graft yield (monomer concentration $60 \%, \mathrm{H}_{2} \mathrm{SO}_{4}$ $2 \%$ of $\mathrm{AN})$. 


\subsection{Conversion of Nitrile Group of AN}

The AN-g-PE films were allowed to react with hydroxylamine hydrochloride to convert the nitrile group to amidoxime group. As shown in Table 1, the conversion of nitrile group of AN molecules increases along with the increase of reaction time at $80 \mathrm{~g} \mathrm{l}^{-1}$ of hydroxylamine hydrochloride solution and $\mathrm{pH}$ 7. The conversion depends on the amount of hydroxylamine diffused from the reaction solution into the AN-g-PE films. Longer reaction times improved the molecular diffusion of hydroxylamine from the solution into the AN-g-PE films and increased the reaction probability between hydroxylamine and the nitrile groups. The increase of hydroxylamine hydrochloride concentration up to $80 \mathrm{~g} \mathrm{l}^{-1}$ also promoted the molecular diffusion of hydroxylamine into the AN-g-PE films. The conversion of nitrile group of AN-g-PE to amidoxine group also depends on $\mathrm{pH}$ of hydroxylamine hydrochloride solution. Maximum conversion was achieved at $\mathrm{pH}$ 7. This could be attributed to the various chemical specifications of hydroxylamine hydrochloride in different $\mathrm{pH}$ conditions. $\mathrm{NH}_{2} \mathrm{OH} \cdot \mathrm{HCl}$ existed in the acid condition, which reduced the amount of free hydroxylamine. At $\mathrm{pH} 7$, hydroxylamine hydrochloride in the solution predominantly existed in the form of free hydroxylamine molecules which accelerated the conversion of nitrile group. Although the alkaline condition caused the formation free hydroxylamine, the molecule would become unstable and volatile.

Table 1: Effect of reaction condition on conversion of nitrile group to amidoxime.

\begin{tabular}{cccc}
\hline Time $(\mathrm{h})$ & $\mathrm{NH}_{2} \mathrm{OH} . \mathrm{HCl}$ content $\left(\mathrm{g}^{-1}\right)$ & $\mathrm{pH}$ & Conversion $(\%)$ \\
\hline 2 & 80 & 7 & 36 \\
3 & 80 & 7 & 65 \\
4 & 80 & 7 & 80 \\
4 & 40 & 7 & 55 \\
4 & 80 & 7 & 80 \\
4 & 160 & 7 & 70 \\
4 & 80 & 5 & 72 \\
4 & 80 & 7 & 80 \\
4 & 80 & 9 & 60 \\
\hline
\end{tabular}

\subsection{FTIR (ATR) Analysis of PE, AN-g-PE and Amidoxime-PE Films}

Polyethylene may be considered as an infinite chain of $\mathrm{CH}_{2}$ groups, therefore the characteristic features of the IR spectrum of PE film (Figure 5) are its C-H stretching vibrations. C-H asymmetric and symmetric stretching vibrations are observed at $2916 \mathrm{~cm}^{-1}$ and $2848 \mathrm{~cm}^{-1}$ respectively. The spectrum for AN-g-PE exhibited a new peak $\left(2245 \mathrm{~cm}^{-1}\right)$ characteristic of nitrile group. After amidoximation of the nitrile 
group of AN-g-PE film the spectra show some changes. The peak corresponding to nitrile group $\left(2245 \mathrm{~cm}^{-1}\right)$ is markedly decreased due to the conversion of nitrile to amidoxime. In addition, the characteristic peaks of amidoxime can be observed at $916 \mathrm{~cm}^{-1}$ (assigned to $\mathrm{N}-\mathrm{O}$ ) and $1220 \mathrm{~cm}^{-1}$ (assigned to the bending vibration of the amine group N-H). Peak broadening occurred around $3736 \mathrm{~cm}^{-1}$ and $3020 \mathrm{~cm}^{-1}$ (assigned to $\mathrm{O}-\mathrm{H}$ ). These results indicate conversion of the nitrile group to the amidoxime group. ${ }^{45,47}$

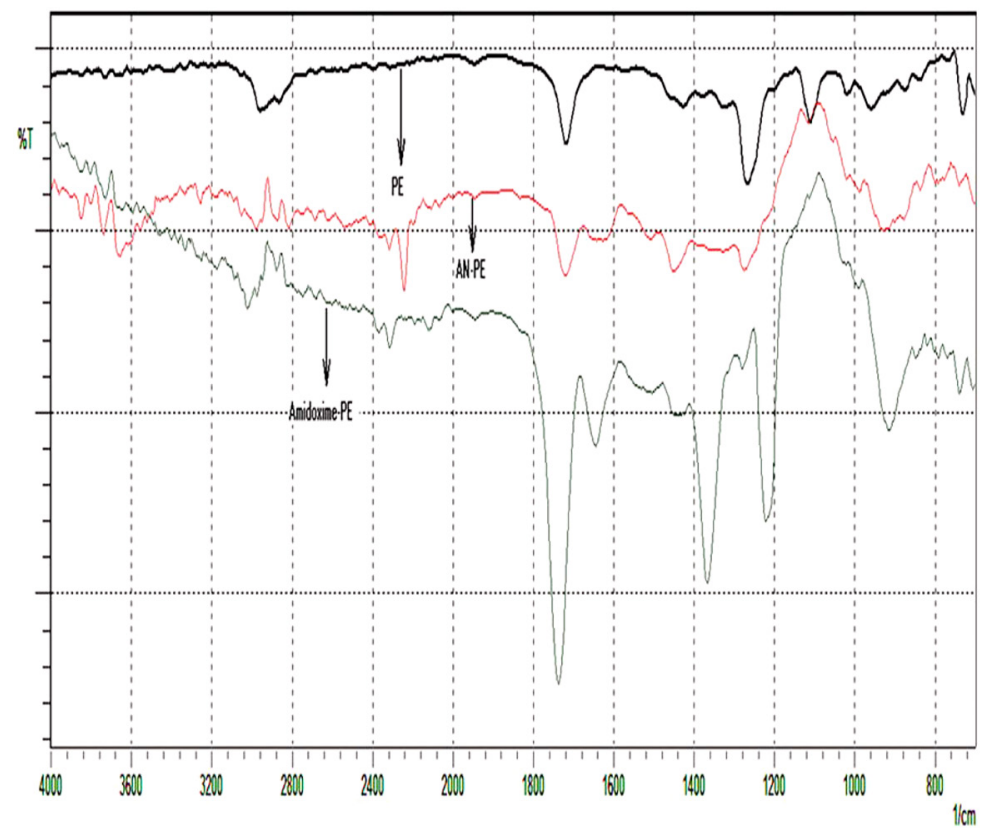

Figure 5: FTIR spectra of PE, AN-g-PE and amidoxime-PE films.

\subsection{NMR Measurements}

Figure 6 shows the nuclear magnetic resonance (NMR) spectra of PE, AN-g$\mathrm{PE}$ and amidoxime-PE. In the spectrum of PE the chemical shifts are as follow: $\delta=0.9 \mathrm{ppm}, \delta=1.2 \mathrm{ppm}$ and $\delta=4.2 \mathrm{ppm}$ corresponding to alkyl(methyl), alkyl(methylene) and vinylic protons respectively. The chemical shifts at $\delta=$ $7.2 \mathrm{ppm}$ is due to the solvent (benzene) used. In the spectrum of AN-g-PE, the intensity of the signals for alkyl(methyl) and alkyl(methylene) protons decreased and vinylic protons disappeared due to radiation induced reaction of PE with AN. Again, in the spectrum of AN-g-PE the intensity of signal at $\delta=1.4 \mathrm{ppm}$ increased which may be due to alkyl(methyne) protons. In the spectrum of amidoxime-PE, increase of intensity of the signal at $\delta=0.4 \mathrm{ppm}$ may be due to the R-OH and $\mathrm{R}-\mathrm{NH}_{2}$ protons. ${ }^{48}$ 


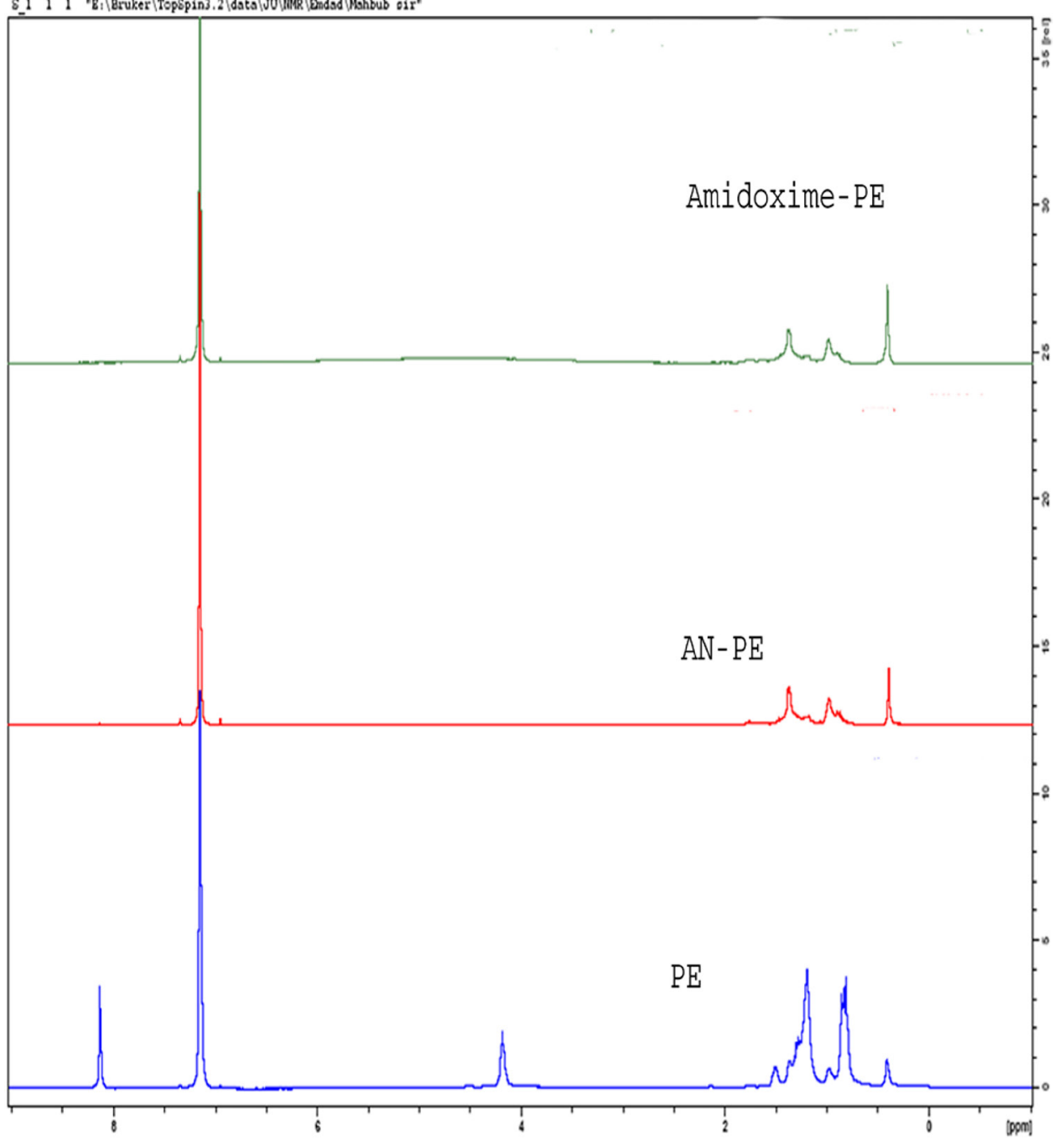

Figure 6: ${ }^{1} \mathrm{H}$ NMR spectra of PE, AN-g-PE and amidoxime-PE films.

\subsection{TGA Analysis of PE, AN-g-PE and Amidoxime-PE Films}

The thermogravimetric analysis (TGA) thermograms for PE film, AN-g-PE film and amidoxime-PE adsorbent are presented in Figure 7. The original PE film shows thermal stability up to $200^{\circ} \mathrm{C}$ and above $200^{\circ} \mathrm{C}$ it starts to decompose. It shows a three decomposition steps, i.e., $200^{\circ} \mathrm{C}-330^{\circ} \mathrm{C}, 330^{\circ} \mathrm{C}-410^{\circ} \mathrm{C}$ and above $410^{\circ} \mathrm{C}$. The thermal stability of AN-g-PE film is higher than that of original PE film. The AN-g-PE fabric remains thermally stable up to $230^{\circ} \mathrm{C}$. The TGA curve of 
the AN-g-PE fabric shows four decomposition processes at the range of $230^{\circ} \mathrm{C}-$ $280^{\circ} \mathrm{C}, 280^{\circ} \mathrm{C}-420^{\circ} \mathrm{C}, 420^{\circ} \mathrm{C}-450^{\circ} \mathrm{C}$ and above $450^{\circ} \mathrm{C}$, due to the degradation of the grafted chain and that of the PE base polymer. There are four weight loss steps in the TGA curve for amidoxime-PE adsorbent. The first weight loss appearing in the temperature range $45^{\circ} \mathrm{C}-100^{\circ} \mathrm{C}$ is easily understood to be due to the loss of moisture absorbed from air. The weight loss stages at $100^{\circ} \mathrm{C}-210^{\circ} \mathrm{C}, 210^{\circ} \mathrm{C}-230^{\circ} \mathrm{C}$ and above $230^{\circ} \mathrm{C}$ originated from degradation of grafted chain and degradation of PE. The weight losses of PE film, AN-g-PE film and amidoxime-PE adsorbent at different temperatures are shown in Table 2.

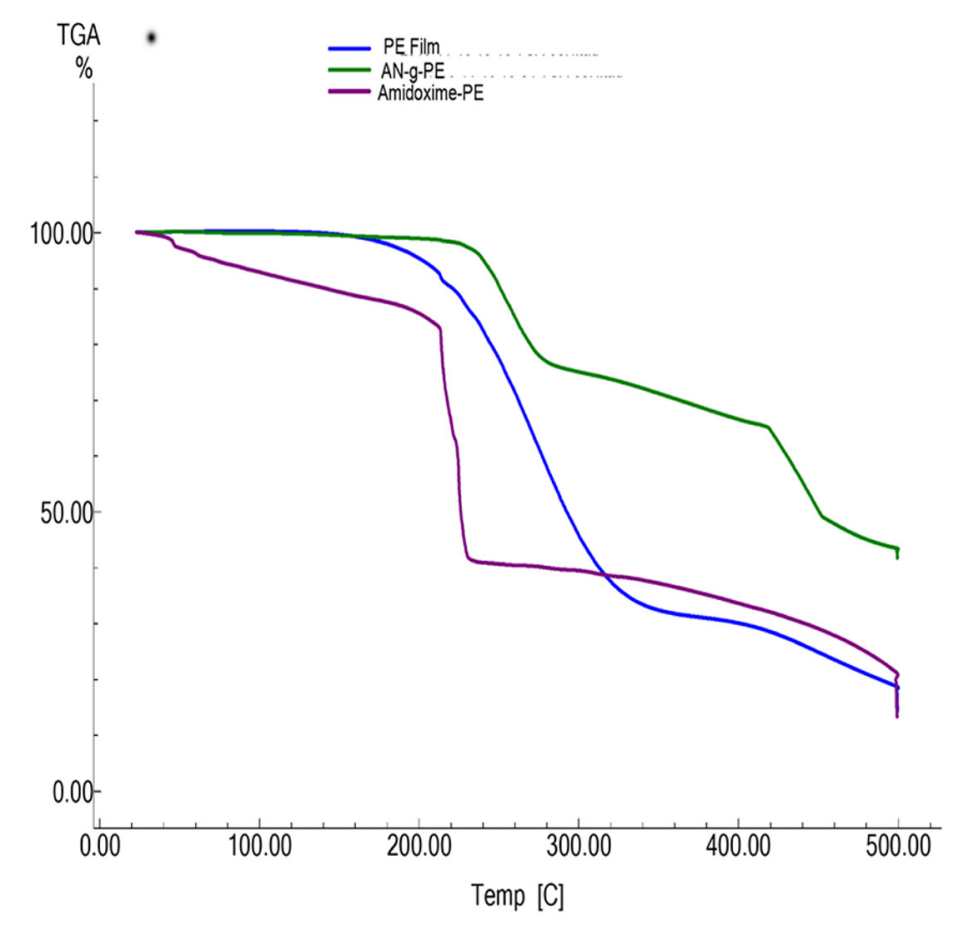

Figure 7: TGA thermograms of PE, AN-g-PE and amidoxime-PE films.

Table 2: The weight losses of PE film, AN-g-PE film and amidoxime-PE adsorbent at different temperatures.

\begin{tabular}{lcrrrrrrr}
\hline \multirow{2}{*}{ Samples } & \multicolumn{7}{c}{ Weight loss $(\%)$} \\
\cline { 2 - 9 } & $100^{\circ} \mathrm{C}$ & $150^{\circ} \mathrm{C}$ & $200^{\circ} \mathrm{C}$ & $250^{\circ} \mathrm{C}$ & $300^{\circ} \mathrm{C}$ & $350^{\circ} \mathrm{C}$ & $400^{\circ} \mathrm{C}$ & $450^{\circ} \mathrm{C}$ \\
\hline PE & 0.00 & 0.12 & 4.39 & 22.39 & 54.04 & 67.41 & 69.70 & 74.95 \\
AN-g-PE & 0.03 & 0.41 & 0.98 & 9.50 & 24.91 & 28.70 & 33.36 & 49.66 \\
Amidoxime-PE & 7.03 & 10.62 & 14.48 & 59.35 & 60.50 & 62.79 & 66.35 & 70.90 \\
\hline
\end{tabular}




\subsection{DMA of PE, AN-g-PE and Amidoxime-PE Films}

Figure 8 reveals the storage modulus of PE, AN-g-PE and amidoxime-PE films with varying temperature. The initial value of storage modulus for AN-g-PE film is higher than that of PE film and amidoxime-PE film. It is observed that the glassy transition region for $\mathrm{AN}-\mathrm{g}-\mathrm{PE}$ film was obtained in the temperature range $49^{\circ} \mathrm{C}-50^{\circ} \mathrm{C}$. On the other hand, the glassy transition region for PE film extends from $30^{\circ} \mathrm{C}$ to $56^{\circ} \mathrm{C}$. Glass transition region for amidoxime-PE film was obtained in the temperature range $34^{\circ} \mathrm{C}-38^{\circ} \mathrm{C}$. It is also found that there is a sharp decrease of modulus in glassy transition region for both AN-g-PE and amidoxime-PE but the PE curve shows a slow decrease of modulus in glassy region.

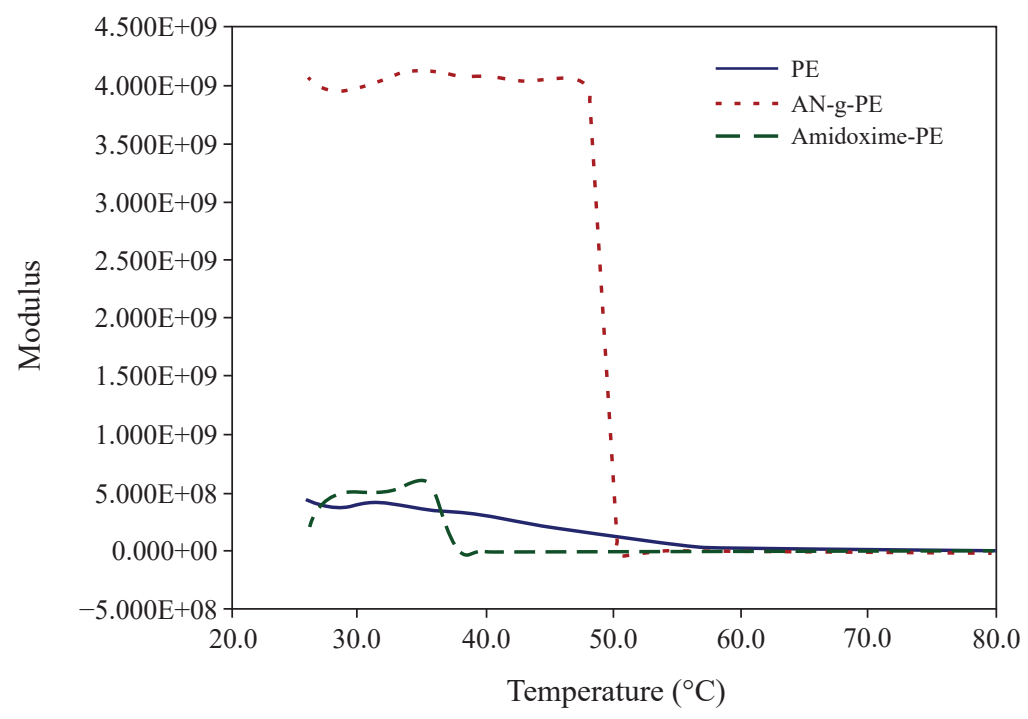

Figure 8: Storage modulus of PE, AN-g-PE and amidoxime-PE films.

\subsection{Cr(VI) Adsorption by Amidoxime-PE Films}

The amidoximated PE films were investigated for adsorption of $\mathrm{Cr}(\mathrm{VI})$ from aqueous solution (Figure 9). The effect of contact time on $\mathrm{Cr}(\mathrm{VI})$ adsorption were examined. The amidoxime-PE films were kept into the aqueous solutions of $\mathrm{Cr}(\mathrm{VI})$ with constant $\mathrm{pH}(\mathrm{pH} 2.2)$ and initial metal ion concentration (100 ppm) at room temperature $\left(25^{\circ} \mathrm{C}\right)$. The concentrations of the $\mathrm{Cr}(\mathrm{VI})$ ions in solution were determined at regular times. The experimental data obtained are shown in Figure 10. It can be observed that the $\mathrm{Cr}(\mathrm{VI})$ adsorption rate is fast at the initial stage of the process, and gradually reaches plateau toward equilibrium with maximum adsorption of $75 \mathrm{mg} \mathrm{g}^{-1}$. The adsorption equilibrium for the adsorption of $\mathrm{Cr}(\mathrm{VI})$ ions was reached after $72 \mathrm{~h}$. 

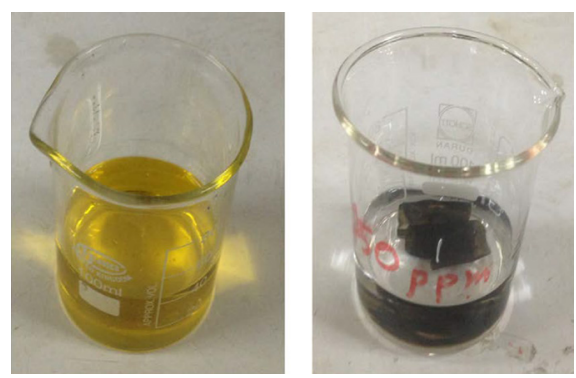

Figure 9: $\mathrm{Cr}(\mathrm{VI})$ solution before (left) and after (right) treatment with amidoxime adsorbent.

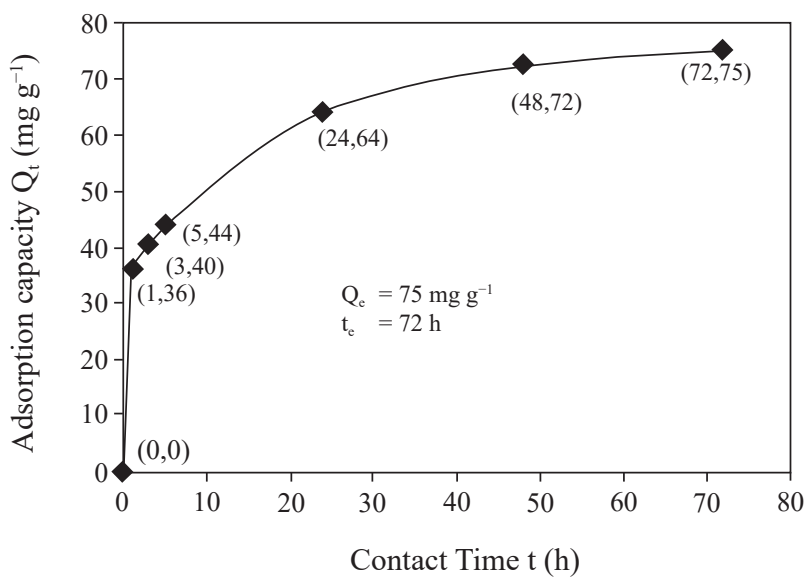

Figure 10: Effect of contact time on $\mathrm{Cr}(\mathrm{VI})$ adsorption capacity ( $\mathrm{pH} 2.2$, initial $\mathrm{Cr}(\mathrm{VI})$ concentration $100 \mathrm{ppm}$ ).

The pseudo-first-order and pseudo-second order kinetic models were applied to fit the $\mathrm{Cr}(\mathrm{VI})$ adsorption by the amidoxime-PE film. The pseudo-first-order and pseudo-second-order equations are expressed as: ${ }^{49,50}$

$$
\begin{aligned}
& \log \left(Q_{e}-Q_{t}\right)=\log Q_{e}-\left(k_{1} / 2.303\right) t \\
& t / Q_{t}=1 /\left(k_{2} Q_{e}{ }^{2}\right)+t / Q_{e}
\end{aligned}
$$

where $\mathrm{Q}_{t}$ and $\mathrm{Q}_{\mathrm{e}}$ are the amount of $\mathrm{Cr}(\mathrm{VI})$ adsorbed $\left(\mathrm{mg} \mathrm{g}^{-1}\right)$ at any time and equilibrium time, respectively, $k_{1}$ is the rate constant $(1 / \mathrm{h})$ of first-order adsorption and $k_{2}\left(\mathrm{~g} \mathrm{~h}^{-1} \mathrm{mg}^{-1}\right)$ is the rate constant of second-order adsorption. The pseudofirst-order rate constants could be determined experimentally by plotting $\log \left(\mathrm{Q}_{\mathrm{e}}-\mathrm{Q}_{\mathrm{t}}\right)$ against $\mathrm{t}$ as shown in Figure 11. The experimental and theoretical $\mathrm{Q}$ e value, first-order rate constant and the correlation coefficients $\left(\mathrm{R}^{2}\right)$ are given 
in Table 3. It can be seen from the results that the experimental Qe value and the Qe value calculated from first order kinetic model are not in agreement with each other. Pseudo-second-order rate constants could be determined experimentally by plotting $t / Q_{t}$ against $t$ as shown in Figure 12. All the second-order kinetic parameters for $\mathrm{Cr}(\mathrm{VI})$ adsorption are also given in Table 3. It can be seen that the experimental $\mathrm{Q}_{\mathrm{e}}$ and the $\mathrm{Q}_{\mathrm{e}}$ values calculated from second-order kinetic model are in accordance with each other. Therefore, the pseudo-second-order equation can be used to interpret $\mathrm{Cr}(\mathrm{VI})$ adsorption on the amidoxime-PE film. Pseudo-secondorder model fit with the experimental kinetic data indicating that intra-particle diffusion process was the rate-limiting step of the adsorption and it also proves that the chelating interaction plays a major role in the adsorption process..$^{51,52}$

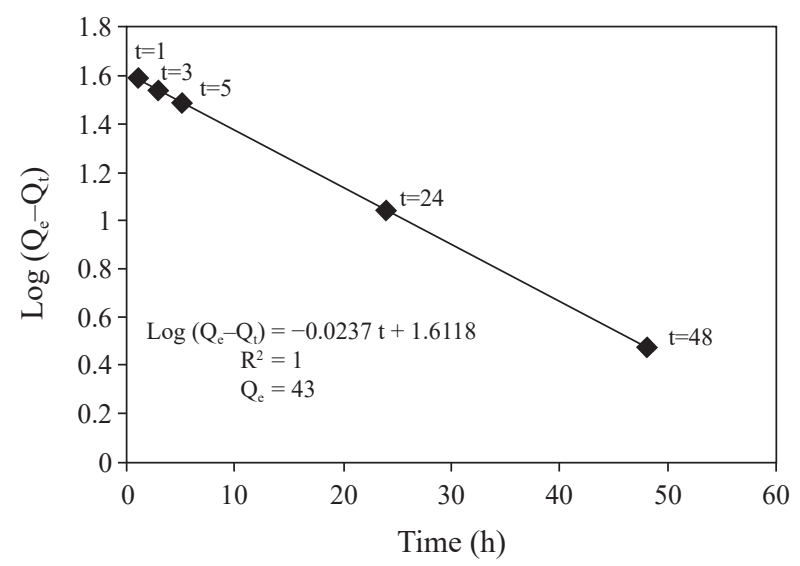

Figure 11: Pseudo-first-order plot for $\mathrm{Cr}(\mathrm{VI})$ adsorption.

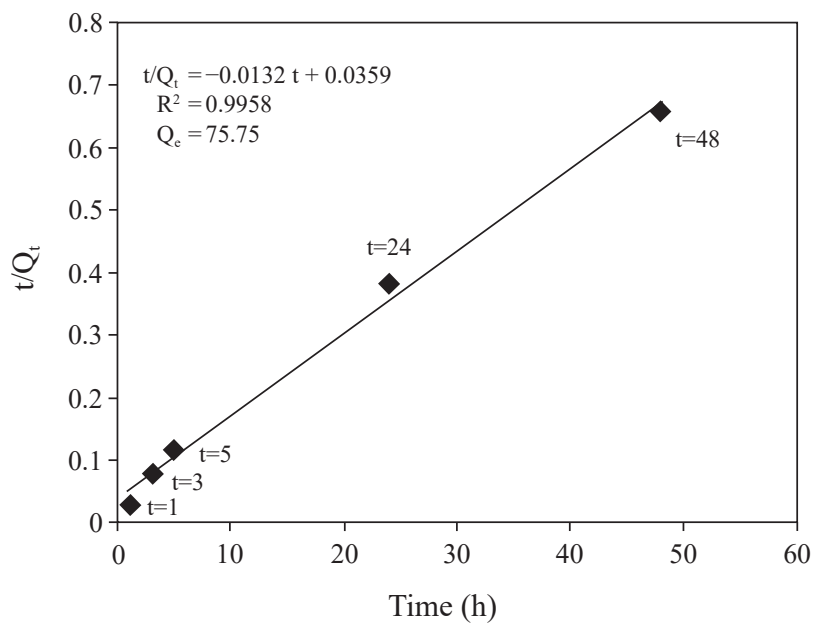

Figure 12: Pseudo-second-order plot Cr(VI) adsorption. 
Table 3: The pseudo-first-order and pseudo-second-order rate constants for $\mathrm{Cr}(\mathrm{VI})$ adsorption by amidoxime adsorbent.

\begin{tabular}{ccccccccc}
\hline \multirow{2}{*}{$\begin{array}{c}\mathrm{Q}_{\mathrm{e}}(\exp .) \\
\left(\mathrm{mg} \mathrm{g}^{-1}\right)\end{array}$} & \multicolumn{2}{c}{ Pseudo-first-order rate constant } & & \multicolumn{3}{c}{ Pseudo-second-order rate constant } \\
\cline { 2 - 3 } & $\begin{array}{c}\left.\mathrm{Q}_{\mathrm{e}} \text { (theor. }\right) \\
\left(\mathrm{mg} \mathrm{g}^{-1}\right)\end{array}$ & $\begin{array}{c}\mathrm{k}_{1} \\
\left(1 \mathrm{~h}^{-1}\right)\end{array}$ & $\mathrm{R}^{2}$ & & $\begin{array}{c}\left.\mathrm{Q}_{\mathrm{e}} \text { (theor. }\right) \\
\left(\mathrm{mg} \mathrm{g}^{-1}\right)\end{array}$ & $\begin{array}{c}\mathrm{k}_{2} \\
\left(\mathrm{~g} \mathrm{~h}^{-1} \mathrm{mg}^{-1}\right)\end{array}$ & $\mathrm{R}^{2}$ \\
\hline 75 & 43 & 0.05458 & 1 & & 75.75 & 0.00485 & 0.9958 \\
\hline
\end{tabular}

It is well known that the $\mathrm{pH}$ of the medium has a great effect on the adsorption capacity of grafted adsorbent, because at different $\mathrm{pH}$ values, due to the protonation and deprotonation behaviours of acidic and basic groups, the surface structure of the adsorbent would be influenced and the metal ions would exist in different forms. The experimental results for the effects of $\mathrm{pH}$ on the adsorption of metal ions are shown in Figure 13. As observed, the adsorption capacity was highly dependent on the $\mathrm{pH}$ with maximum adsorption at $\mathrm{pH}=1.5$. The amount of $\mathrm{Cr}(\mathrm{VI})$ removal decreased with increasing $\mathrm{pH}$ of $\mathrm{Cr}(\mathrm{VI})$ solution. The variation of the adsorption capacity of the adsorbent at different $\mathrm{pH}$ values may be attributed to the affinities of the amidoxime-PE adsorbent for the different species of $\mathrm{Cr}(\mathrm{VI})$ that exist in acidic $\mathrm{pH}$ values namely $\mathrm{H}_{2} \mathrm{CrO}_{4}, \mathrm{HCrO}_{4}^{-}, \mathrm{CrO}_{4}^{2-}$ and $\mathrm{Cr}_{2} \mathrm{O}_{7}^{2-}$. At low $\mathrm{pH}$ value, the $\mathrm{NH}_{2}$ groups on the surface of the amidoxime-PE film are protonated to form $\mathrm{NH}_{3}{ }^{+}$(positively charge) which easily bind to the negatively charged species due to the electronic attraction. At high $\mathrm{pH}$ value, the $\mathrm{NH}_{2}$ groups of the amidoxime-PE are de-protonated to form $\mathrm{NH}_{2} \ldots \mathrm{OH}^{-}$which electrostatically repel the negatively charged $\mathrm{Cr}(\mathrm{VI})$ species and thus the adsorption decreases.

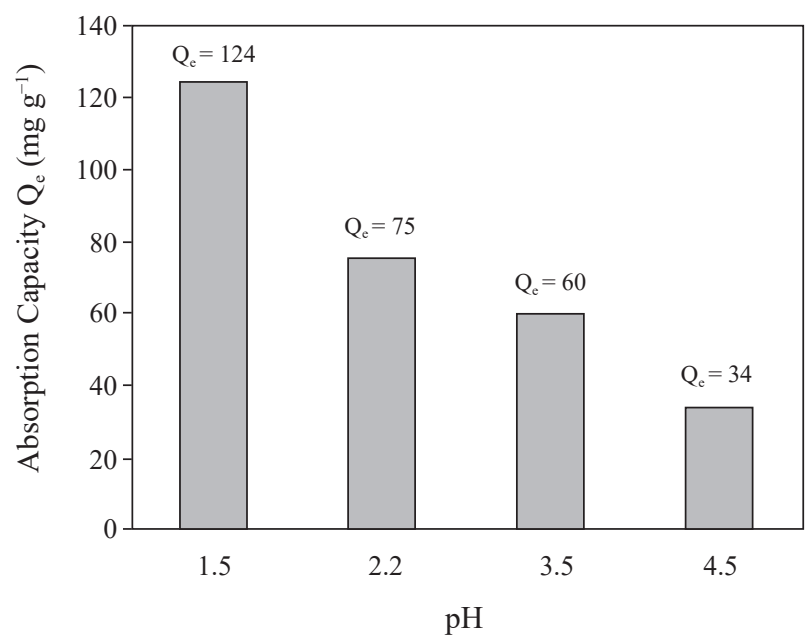

Figure 13: Effect of $\mathrm{pH}$ on $\mathrm{Cr}(\mathrm{VI})$ adsorption (contact time $72 \mathrm{~h}$, initial $\mathrm{Cr}(\mathrm{VI})$ concentration $100 \mathrm{ppm})$. 
Figure 14 shows the relationship between the initial concentration of metal ions and the adsorption capacity. The figure shows that the adsorption amount of metal ions increased with increasing initial metal ion concentration then reached a plateau at higher concentration. This is due to the fact that the chelating sites of the adsorbent become saturated when the metal ion concentration increases. For interpretation of the $\mathrm{Cr}(\mathrm{VI})$ adsorption data, the Langmuir isotherm model is used. The linear form of the Langmuir isotherm model is presented by:

$$
\mathrm{C}_{\mathrm{e}} / \mathrm{Q}_{\mathrm{e}}=\mathrm{C}_{\mathrm{e}} / \mathrm{Q}_{\mathrm{o}}+1 /\left(\mathrm{Q}_{\mathrm{o}} \mathrm{b}\right)
$$

where $\mathrm{C}_{\mathrm{e}}$ is the equilibrium concentration $\left(\mathrm{mg} \mathrm{l}^{-1}\right), \mathrm{Q}_{\mathrm{o}}$ is the monolayer saturation adsorption capacity of the adsorbent $\left(\mathrm{mg} \mathrm{g}^{-1}\right), \mathrm{Q}_{\mathrm{e}}$ is the equilibrium adsorption capacity and $b$ is the Langmuir adsorption constant $\left(1 \mathrm{mg}^{-1}\right)$. The plot of $\mathrm{C}_{\mathrm{e}} / \mathrm{Q}_{\mathrm{e}}$ versus $\mathrm{C}_{\mathrm{e}}$ shown in Figure 15 was drawn from the experimental data given in Figure 14. The relationship between $\mathrm{C}_{\mathrm{e}} / \mathrm{Q}_{\mathrm{e}}$ and $\mathrm{C}_{\mathrm{e}}$ is linear indicating that the adsorption behaviour follows the Langmuir adsorption isotherm. From the Langmuir equation the monolayer saturation adsorption capacity of the adsorbent was found to be $200 \mathrm{mg} \mathrm{g}^{-1}$. Cr(VI) adsorption capacity of amidoxime-PE film compared with some other adsorbents are shown in Table 4.

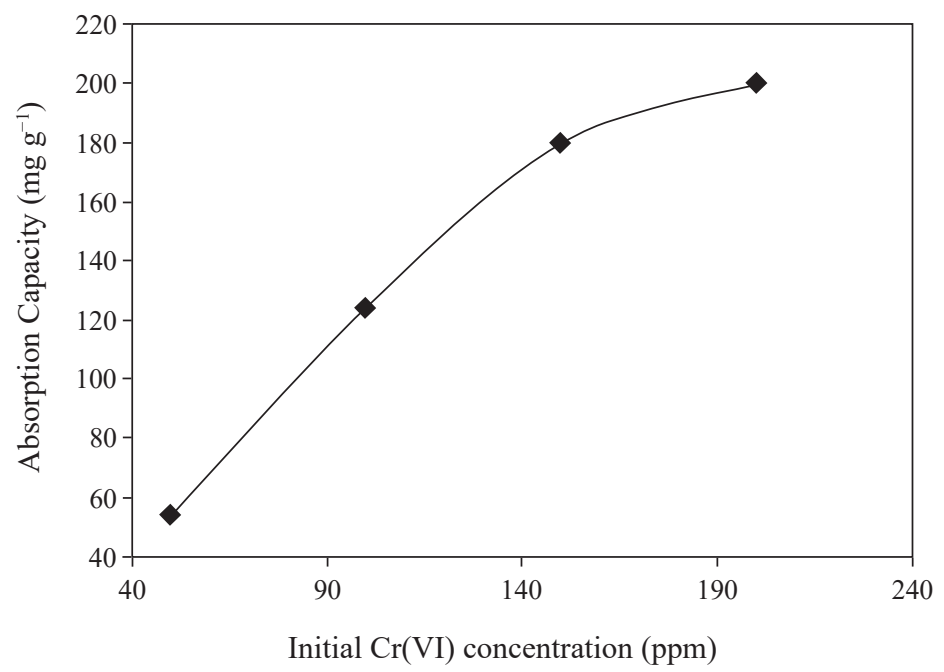

Figure 14: Effect of initial $\mathrm{Cr}(\mathrm{VI})$ concentration on adsorption capacity (contact time $72 \mathrm{~h}$, $\mathrm{pH} 1.5)$. 


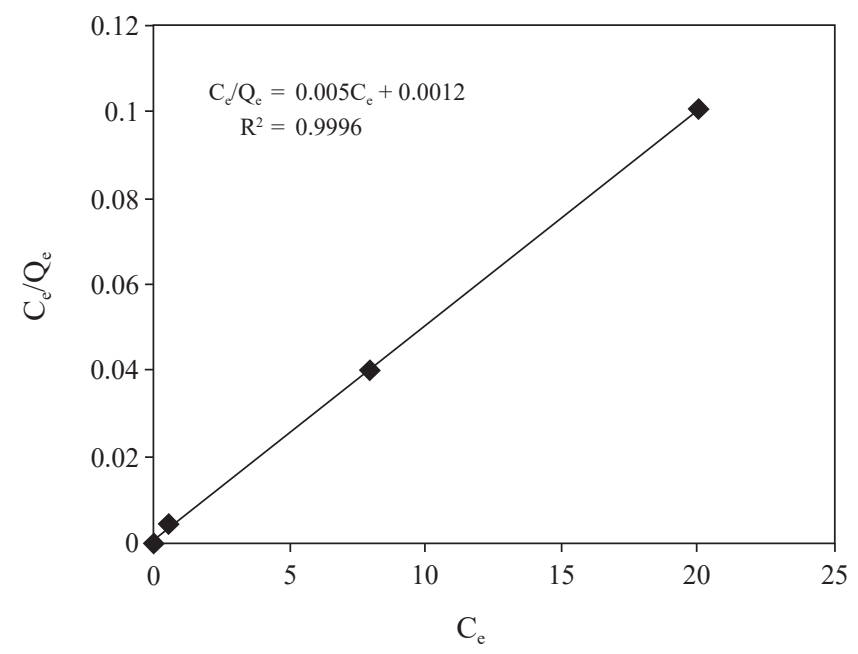

Figure 15: Langmuir isotherm plot for $\mathrm{Cr}(\mathrm{VI})$ adsorption.

Table 4: $\mathrm{Cr}(\mathrm{VI})$ adsorption capacity of amidoxime-PE adsorbent compared with some other adsorbents.

Adsorbent

Adsorption capacity

Amidoxime-PE (present study) $\left(\mathrm{mg} \mathrm{g}^{-1}\right)$

Palm trunk charcoal ${ }^{53}$ 200

Activated carbon derived from acrylonitrile-divinylbenzene co-polymer ${ }^{54}$

Chemically modified banana peels ${ }^{55}$

101.2

Amine functionalised nanofibres ${ }^{45}$

Ethylenediamine-modified cross-linked magnetic chitosan resin ${ }^{56}$

Chitosan-ionic liquid ${ }^{57}$

Modified red pine sawdust ${ }^{58}$

PAN/Ppy core shell nanofibres ${ }^{59}$

74.9

After adsorption of metal ions on the amidoxime-PE film, the adsorbents were regenerated using $2 \mathrm{M}$ sodium hydroxide solution. Desorption equilibrium was achieved after $20 \mathrm{~h}$. The desorption ratio was $99 \%$. The sorption capacity of the film for $\mathrm{Cr}(\mathrm{VI})$ adsorption from aqueous solutions in five successive cycles is shown in Figure 16. The sorption capacity does not show significant change upon repeated use of the film for $\mathrm{Cr}(\mathrm{VI})$ adsorption. 


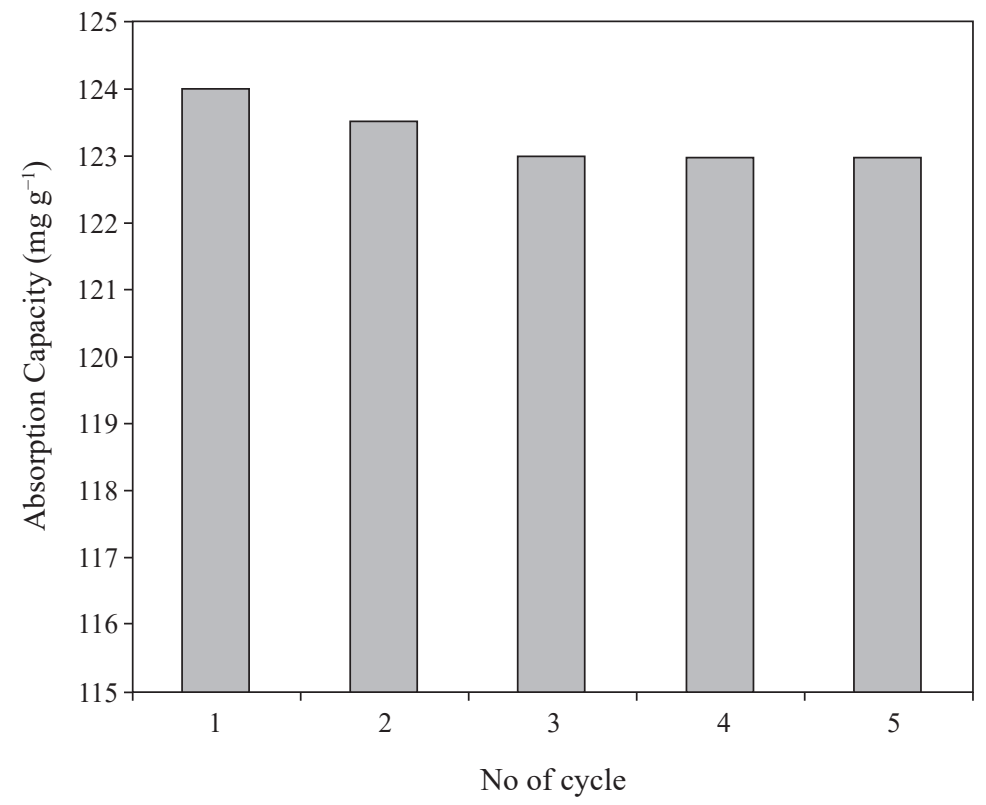

Figure 16: Repeated use of amidoxime-PE film for adsorption of $\mathrm{Cr}(\mathrm{VI})$ ( $\mathrm{pH} 1.5$, contact time $72 \mathrm{~h}$, initial $\mathrm{Cr}(\mathrm{VI})$ concentration $100 \mathrm{ppm}$ ).

\section{CONCLUSION}

Successful preparation of AN-g-PE films was conducted using pre-irradiation technique. $\mathrm{H}_{2} \mathrm{SO}_{4}$ as additive was found to increase the graft yield significantly. Highest graft yield obtained was $120 \%$ at $70 \mathrm{kGy}$ radiation dose, $60 \%$ monomer concentration and $4 \mathrm{~h}$ reaction time using $\mathrm{H}_{2} \mathrm{SO}_{4}$ as additive. The $\mathrm{AN}$ grafted films were modified with hydroxylamine hydrochloride to prepare amidoxime adsorbent. The prepared adsorbent was characterised by FTIR, NMR, TGA and DMA. The prepared amidoxime adsorbent showed high affinity towards $\mathrm{Cr}(\mathrm{VI})$ adsorption. The highest adsorption capacity obtained was $200 \mathrm{mg} / \mathrm{g}$ after $72 \mathrm{~h}$ contact time at $\mathrm{pH} 1.5$ and initial metal ion concentration $200 \mathrm{ppm}$. Kinetics and isotherm of $\mathrm{Cr}(\mathrm{VI})$ adsorption were studied. The experimental data for the adsorption of $\mathrm{Cr}(\mathrm{VI})$ on amidoxime adsorbent fitted with pseudo-second order kinetic model and Langmuir isotherm model. Desorption and reuse of the adsorbent film were also successful. 


\section{ACKNOWLEDGEMENTS}

The authors are pleased to acknowledge the International Atomic Energy Agency (IAEA) for technical support to carry out the research. Authors also would like to thank the Gamma Source Division of Institute of Food and Radiation Biology, Atomic Energy Research Establishment for providing us the opportunity to use the irradiation facility.

\section{REFERENCES}

1. Adriano, D. C. (1986). Trace elements in the terrestrial environment. New York: Springer, https://doi.org/10.1007/978-0-387-21510-5.

2. Afkhami, A. \& Conway, B. E. (2002). Investigation of removal of $\mathrm{Cr}(\mathrm{VI})$, $\mathrm{Mo}(\mathrm{VI}), \mathrm{W}(\mathrm{VI}), \mathrm{V}(\mathrm{IV})$, and $\mathrm{V}(\mathrm{V})$ oxy-ions from industrial waste-waters by adsorption and electrosorption at high-area carbon cloth. J. Coll. Interf. Sci., 251, 248-255, https://doi.org/10.1006/jcis.2001.8157.

3. Cimino, G., Passerini, A. \& Toscano, G. (2000). Removal of toxic cations and $\mathrm{Cr}(\mathrm{VI})$ from aqueous solution by hazelnut shell. Water Res., 34, 29552962, https://doi.org/10.1016/S0043-1354(00)00048-8.

4. Kanwal, F. et al. (2012). Batchwise removal of chromium (VI) by adsorption on novel synthesized polyaniline composites with various brans and isothermal modeling of equilibrium data. J. Chem. Soc. Pak., 34, 1134-1139.

5. Nriagu, J. O. \& Nieboer, E. (1988). Chromium in the natural and human environment. New York: Wiley.

6. Belay, A. A. (2010). Impacts of chromium from tannery effluent and evaluation of alternative treatment options. J. Environ. Protect., 1, 53-58, https://doi.org/10.4236/jep.2010.11007.

7. Marques, M. J. et al. (2000). Chromium speciation in liquid matrices: A survey of the literature. Fresenius J. Anal. Chem., 367, 601-613, https://doi.org/10.1007/s002160000422.

8. Sperling, M., Xu, S. \& Welz, B. (1992). Determination of chromium(III) and chromium(VI) in water using flow injection on-line preconcentration with selective adsorption on activated alumina and flame atomic absorption spectrometric detection. Anal. Chem., 64, 3101-3108, https://doi.org/ $10.1021 / \mathrm{ac} 00048 \mathrm{a} 007$.

9. Assem, L. \& Zhu, H. (2007). Chromium general information. Cranfield: Institute of Environment and Health, Cranfield University.

10. Zhang, L. S. (2009). The advanced water treatment and reuse technology. Beijing: Chemical Industry Press. 
11. Cheng, C. J. et al. (2009). The effectiveness of ferrous iron and sodium dithionite for decreasing resin-extractable $\mathrm{Cr}(\mathrm{VI})$ in $\mathrm{Cr}(\mathrm{VI})$-spiked alkaline soils. J. Hazard. Mater, 164, 510-516, https://doi.org/10.1016/j. jhazmat.2008.08.037.

12. Salazar, E. et al. (1992). Equilibrium and kinetics of the $\mathrm{Cr}(\mathrm{VI})$ extraction with Aliquat 336. Ind. Eng. Chem. Res., 31, 1516-1522, https://doi. org/10.1021/ie00006a014.

13. Ahmed, M. T. et al. (2006). Nanofiltration process applied to the tannery solutions. Desalin., 200, 419-420, https://doi.org/10.1016/j. desal.2006.03.354.

14. Ahn, C. K. et al. (2009). Removal of cationic heavy metal from aqueous solution by activated carbon impregnated with anionic surfactants. J. Hazard. Mater., 164, 1130-1136, https://doi.org/10.1016/j.jhazmat. 2008.09.036.

15. Park, S. J. \& Jang, Y. S. (2002). Pore structure and surface properties of chemically modified activated carbons for adsorption mechanism and rate of Cr(VI). J. Coll. Interf. Sci., 249, 458-463, https://doi.org/10.1006/ jcis.2002.8269.

16. Schneider, R. M. et al. (2007). Adsorption of chromium ions in activated carbon. Chem. Eng. J., 132, 355-362, https://doi.org/10.1016/j. cej.2007.01.031.

17. Hu, Z. et al. (2003). Chromium adsorption on high-performance activated carbons from aqueous solution. Sep. Purif. Technol., 31, 13-18, https://doi. org/10.1016/S1383-5866(02)00149-1.

18. Gupta, V. K. \& Ali, I. (2013). Environmental water, advances in treatment, remediation and recycling. Amsterdam: Elsevier.

19. Albadarin, A. B. et al. (2012). Influence of solution chemistry on $\mathrm{Cr}(\mathrm{VI})$ reduction and complexation onto date-pits/tea-waste biomaterials. J. Environ. Manage., 114, 190-201, https://doi.org/10.1016/j.jenvman.2012.09.017.

20. Park, D., Yun, Y. S. \& Park, J. M. (2006). Mechanisms of the removal of hexavalent chromium by biomaterials or biomaterial-based activated carbons. J. Hazard. Mater., 137, 1254-1257, https://doi.org/10.1016/j. jhazmat.2006.04.007.

21. Saha, B. \& Orvig, C. (2010). Biosorbents for hexavalent chromium elimination from industrial and municipal effluents. Coord. Chem. Rev., 254, 2959-2972, https://doi.org/10.1016/j.ccr.2010.06.005.

22. Hou, Y. et al. (2012). Combination of electroreduction with biosorption for enhancement for removal of hexavalent chromium. J. Coll. Interf. Sci., 385, 147-153, https://doi.org/10.1016/j.jcis.2012.05.056. 
23. Burks, T. et al. (2013). Removal of chromium(VI) using surface modified superparamagnetic iron oxide nanoparticles. Sep. Sci. Technol., 48, 12431251, https:// doi.org/10.1080/01496395.2012.734364.

24. Ponder, S. M., Darab, J. G. \& Mallouk, T. E. (2000). Remediation of Cr(VI) and $\mathrm{Pb}(\mathrm{II})$ aqueous solutions using supported, nanoscale zero-valent iron. Environ. Sci. Technol., 34, 2564-2569, https://doi.org/10.1021/es9911420.

25. Coşkun, R. \& Soykan, C. (2006). Lead(II) adsorption from aqueous solution by poly(ethylene terephthalate)-g-acrylamide. Fib. J. Polym. Res., 13, 1-8, https://doi.org/10.1007/s10965-005-9000-3.

26. Băg, H. et al. (2000). Determination of zinc, cadium, cobalt and nickel by flame atomic absorption spectrometry after preconcentration by poly ethylene terephthalate/fibers grafted with methacrylic acid. Spectrochim. Acta B, 55, 1101-1108, https://doi.org/10.1016/S0584-8547(00)00162-2.

27. Bozkaya, O., Yiğitoğlu, M. \& Arslan, M. (2012). Investigation on selective adsorption of $\mathrm{Hg}(\mathrm{II})$ ions using 4-vinyl pyridine grafted poly(ethylene terephthalate) fiber. J. Appl. Polym. Sci., 124, 1256-1264, https://doi. org/10.1002/app.35143.

28. Çoşkun, R., Soykan, C. \& Saçak, M. (2006). Adsorption of copper(II), nickel(II) and cobalt(II) ions from aqueous solution by methacrylic acid/ acrylamide monomer mixture grafted poly(ethylene terephthalate) fiber. Sep. Purif. Technol., 49, 107-114, https://doi.org/10.1016/j.seppur.2005. 09.002.

29. Coşkun, R., Soykan, C. \& Saçak, M. (2006). Removal of some heavy metal ions from aqueous solution by adsorption using poly(ethylene terephthalate)-g-itaconic acid/acrylamide fiber. React. Funct. Polym., 66, 599-608, https://doi.org/10.1016/j.reactfunctpolym.2005.10.012.

30. Arslan, M. (2010). Preparation and use of amine-functionalized glycidyl methacrylate-g-poly(ethylene terephthalate) fibers for removal of chromium(VI) from aqueous solution. Fiber Polym., 11, 325-330, https://doi.org/10.1007/s12221-010-0325-0.

31. Yiğitoğlu, M. \& Arslan, M. (2005). Adsorption of hexavalent chromium from aqueous solutions using 4-vinyl pyridine grafted poly(ethylene terephthalate) fibers. Polym. Bull., 55, 259-268, https://doi.org/10.1007/ s00289-005-0440-z.

32. Yiğitoğlu, M. \& Arslan, M. (2009). Selective removal of $\mathrm{Cr}(\mathrm{VI})$ ions from aqueous solutions including $\mathrm{Cr}(\mathrm{VI}), \mathrm{Cu}(\mathrm{II})$ and $\mathrm{Cd}(\mathrm{II})$ ions by 4-vinly pyridine/2-hydroxyethylmethacrylate monomer mixture grafted poly(ethylene terephthalate) fiber. J. Hazard. Mater., 166, 435-444, https://doi.org/10.1016/j.jhazmat.2008.11.075. 
33. Karakısla, M. (2003). The adsorption of $\mathrm{Cu}(\mathrm{II})$ ion from aqueous solution upon acrylic acid grafted poly(ethylene terephthalate) fibers. J. Appl. Polym. Sci., 87, 1216-1220. https://doi.org/10.1002/app.11578.

34. Hamada, H., Razik, A. \& Kenawy, E. R. (2012). Synthesis, characterization, and amidoximation of diaminomaleodinitrile-functionalized polyethylene terephthalate grafts for collecting heavy metals from wastewater. J. Appl. Polym. Sci., 125, 1136-1145, https://doi.org/10.1002/app.34832.

35. Ping, X., Wangn, M. \& Ge, X. (2011). Radiation induced graft copolymerization of n-butyl acrylate onto poly(ethylene terephthalate) (PET) films and thermal properties of the obtained graft copolymer. Radiat. Phys. Chem., 80, 632-637, https://doi.org/10.1016/j.radphyschem.2011.01.001.

36. Hsieh, L., Shinawatra, Y. M. \& Castillo, M. D. (1986). Postirradiation polymerization of vinyl monomers on poly(ethylene terephthalate). J. Appl. Polym. Sci., 31, 509-519, https://doi.org/10.1002/app.1986.070310218.

37. Abdel-Bary, E. M., Sarhan, A. A. \& Abdel-Razik, H. H. (1986). Effect of graft copolymerization of 2-hydroxyethyl methacrylate on the properties of polyester fibers and fabric. J. Appl. Polym. Sci., 35, 439-448, https://doi. org/10.1002/app.1988.070350211.

38. Nasef, M. M. (2000). Gamma radiation-induced graft copolymerization of styrene onto poly(ethylene terephthalate) films. J. Appl. Polym. Sci., 77, 1003-1012, https://doi.org/10.1002/1097-4628(20000801)77:5<1003:: AID-APP7>3.0.CO;2-K.

39. Hegazy, E. A. et al. (1999). Membranes prepared by radiation grafting of binary monomers for adsorption of heavy metals from industrial wastes. Nucl. Instrum. Methods Phys. Res. B, 151, 386-392, https://doi.org/10.1016/ S0168-583X(99)00125-1.

40. Hegazy, E. A. et al. (2001). Separation and extraction of some heavy and toxic metal ions from their wastes by grafted membranes. J. Appl. Polym. Sci., 81, 849-860, https://doi.org/10.1002/app.1504.

41. Hegazy, E. A. et al. (1999). Characterization and application of radiation grafted membranes in treatment of intermediate active waste. Nucl. Instrum. Methods Phys. Res. B, 151, 393-398, https://doi.org/10.1016/S0168583X(99)00107-X

42. Abd El-Rehim, H. A., Hegazy, E. A. \& Ali, A. E. (2000). Selective removal of some heavy metal ions from aqueous solution using treated polyethyleneg-styrene /maleic anhydride membranes. React. Funct. Polym., 43, 105-116, https://doi.org/10.1016/S1381-5148(99)00009-7.

43. Asamoto, H. et al. (2016). Use of polyethylene films photografted with 2-(dimethylamino)ethyl methacrylate as a potential adsorbent for removal of chromium (VI) from aqueous medium. J. Appl. Polym. Sci., 133, 43360, https://doi.org/10.1002/app.43360. 
44. García-Rosales, G. et al. (2014). Using plasma $\mathrm{TiO}_{\mathrm{x}}$-polyethylene composites for removing $\mathrm{Cr}(\mathrm{VI})$. Adsorpt. Sci. Technol., 32, 499-508, https://doi. org/10.1260/0263-6174.32.6.499.

45. Avila, M. et al. (2014). Surface functionalized nanofibers for the removal of chromium(VI) from aqueous solutions. Chem. Eng. J., 245, 201-209, https://doi.org/10.1016/j.cej.2014.02.034.

46. Bhattacharya, A. \& Misra, B. N. (2004). Grafting: A versatile means to modify polymers Techniques, factors and applications. Prog. Polym. Sci., 29, 767-814, https://doi.org/10.1016/j.progpolymsci.2004.05.002.

47. Ramasamy R. (2015). Vibrational spectroscopic studies of imidazole. Arm. J. Phys., 8, 51-55.

48. Silverstein, R. M., Webster, F. X. \& Kiemle, D. J. (2005). Spectrometric identification of organic compounds, 7th ed. New York: John Wiley \& Sons.

49. Ho, Y. S. (2006). Review of second-order models for adsorption systems. J. Hazard. Mater., 136, 681-689, https://doi.org/10.1016/j. jhazmat.2005.12.043.

50. Namasivayam, C. \& Arasi, D. J. S. E. (1997). Removal of Congo red from wastewater by adsorption onto waste red mud. Chemosph., 34, 401-417, https://doi.org/10.1016/S0045-6535(96)00385-2.

51. Rengaraj, S. et al. (2007). Adsorption characteristics of $\mathrm{Cu}(\mathrm{II})$ onto ion exchange resins $252 \mathrm{H}$ and $1500 \mathrm{H}$ : Kinetics, isotherms and error analysis. J. Hazard. Mater., 143, 469-477, https://doi.org/10.1016/j. jhazmat.2006.09.064.

52. Li, Y., Yue, Q. Y. \& Gao, B. Y. (2010). Adsorption kinetics and desorption of $\mathrm{Cu}(\mathrm{II})$ and $\mathrm{Zn}(\mathrm{II})$ from aqueous solution onto humic acid. J. Hazard. Mater., 178, 455-461, https://doi.org/10.1016/j.jhazmat.2010.01.103.

53. Yadav, S. K. \& Dixit, A. K. (2016). Efficient removal of Cr(VI) from aqueous solution onto palm trunk charcoal: Kinetic and equilibrium studies. Chem. Sci. J., 7, 1-7, http://dx.doi.org/10.4172/2150-3494.1000114.

54. Duranoğlu, D., Trochimczuk, A. W. \& Bekera, U. (2012). Kinetics and thermodynamics of hexavalent chromium adsorption onto activated carbon derived from acrylonitrile-divinylbenzene copolymer. Chem. Eng. J., 187, 193-202, https://doi.org/10.1016/j.cej.2012.01.120.

55. Ali, A., Saeed, K. \& Mabood, F. (2016). Removal of chromium (VI) from aqueous medium using chemically modified banana peels as efficient lowcost adsorbent, Alexandr. Eng. J., 55, 2933-2942, https://doi.org/10.1016/j. aej.2016.05.011.

56. Hu, X. J. et al. (2011). Adsorption of chromium (VI) by ethylenediaminemodified cross-linked magnetic chitosan resin: Isotherms, kinetics and thermodynamics. J. Hazard. Mater., 185, 306-314, https://doi.org/10.1016/j. jhazmat.2010.09.034. 
57. Kumar, A. S. K. et al. (2012). Effective adsorption of hexavalent chromium through a three center (3C) cooperative interaction with an ionic liquid and biopolymer. J. Hazard. Mater., 239-240, 213-224, https://doi.org/10.1016/j. jhazmat.2012.08.065.

58. Gode, F., Atalay, E. D. \& Pehlivan, E. (2008). Removal of Cr(VI) from aqueous solutions using modified red pine sawdust. J. Hazard. Mater., 152, 1201-1207, https://doi.org/10.1016/j.jhazmat.2007.07.104.

59. Wang, J. et al. (2013). Polyacrylonitrile/polypyrrole core/shell nanofiber mat for the removal of hexavalent chromium from aqueous solution. J. Hazard. Mater., 244-245, 121-129, https://doi.org/10.1016/j.jhazmat.2012.11.020. 